\title{
Obesity and lifestyle indicators impact on obstetric complications and fetal outcome in North Lebanon population
}

\author{
Mayssa A. Traboulsi; Abdellatif Boussaid; Zainab. El Alaoui Talibi \\ Laboratory of Biotechnology and Molecular Engineering, Faculty of Sciences and Techniques, Cadi \\ Ayyad University, city zip: 40000, Marrakech. \\ Morocco.
}

Received: July 7, 2020. Revised: January 3, 2021. Accepted: January 19, 2021. Published: January 24, 2021.

\begin{abstract}
Worldwide, obesity has been shown to negatively affect women especially during pregnancy. In this work, a retrospective cohort study for 1308 women, who gave birth between 2014 and 2016 in public and private hospitals, was conducted to evaluate the impact of weight, demographic and lifestyle indicators on many pregnancy and fetal outcomes in Northern Lebanon. The frequent health complications related to pregnancy were cesarean-section (31.1\%) followed by post-hemorrhage $(25.1 \%)$, induced labor $(23.5 \%)$ and macrosomia $(\mathbf{1 1 . 4 \% )}$. Multivariate analysis showed that the main complications were highly correlated to obesity, macrosomia, weight gain, multiparity and mother's age. High values from adjusted odds ratios were mainly associated to obesity, multiparity and weight gain. Obese pregnant women had a significant increased risk of having cesarean-section $(p<0.001)$, preeclampsia $(p<0.0001)$, labor induction $(p<0.0001)$ and postpartum hemorrhage $(p<0.0001)$. Adverse fetal outcomes such as macrosomia were also correlated with high BMI $(p<0.0001)$. The risk was even greater for multiparous, older women that carried excessive weight gain. There is therefore a need to increase awareness among the target population and encourage prevention of the dangers related to obesity and weight gain.
\end{abstract}

Keywords-Body mass index; pregnancy complications; fetal outcomes; weight gain; multiparity.

\section{INTRODUCTION}

A dverse obstetric and newborn complications are increasingly becoming a public health concern in many countries especially in Asia and Africa [1]. They have been mainly associated to pregnancy weight parameters, especially high early pregnancy Body mass index (BMI) [2].
Obesity and overweight are increasingly considered global health problems [3]. The prevalence of overweight adult women increased from $29.8 \%$ in 1980 to $38 \%$ in 2013 worldwide, especially in middle-income countries [4]. In developed countries particularly in the United States prepregnancy, overweight/obesity was evaluated at $42 \%$ [5]. Similar trends were reported during the last decades across Europe with a prevalence of obesity in pregnant women more

than $30 \%$ in the majority of European Countries [6,7] reaching over $48 \%$ in Scotland [8]. The proportion of maternal obesity in Africa ranged from 6,5\% to 50.7\% [9] Furthermore, the study conducted by Cheng et al [10] from 2005 to 2014 in 184 countries revealed that the number of overweight and obese pregnant women increased rapidly in middle income Asian countries especially India, China, Turkey, Iran, Iraq and Saudi Arabia [10].

Data from the MENA region (Middle East and North Africa) are relatively scarce; nevertheless, few studies have shown a correlation of obstetric complications to obesity for Egypt [11] Morocco [12], Turkey [13] and Iran [14]. In addition, the Eastern Mediterranean region is also facing an epidemic of obesity since statistics highlight an alarming rise of obesity, especially in the Arab world [15]. In Lebanon, $49.4 \%$ of the adult women are overweight while $14.3 \%$ of them struggling with obesity [16] that is becoming a national public health concern [17]. In addition, the prevalence of csection (cesarean section) in Lebanon reached 49\% [18]. Moreover, a study conducted in Lebanon has reported on the impact of excessive gestational weight gain on preterm births among normal and overweight women [19].

For weight control during pregnancy, the institute of Medicine guidelines show that underweight women can gain weight during their pregnancy between 18-40 pounds, normal weight women can gain between 25-35 pounds, overweight 
women can gain between 15-25 and obese women can gain between 11-20 pounds [20].

Obesity increases the risk of pregnancy-associated disorders $[21,22]$. A $10 \%$ difference in pre-pregnancy BMI is associated with at least $10 \%$ change in relative risk of preeclampsia and gestational diabetes, respectively [23]. A pre-pregnancy BMI $>25 \mathrm{~kg} / \mathrm{m}^{2}$ is associated with an increased risk of developing diabetes mellitus and cardiac disease. In addition to that, gestational weight gain of more than $15 \mathrm{~kg}$ increases the risk of becoming obese later in life [24]. The preterm birth rate is increased by obesity and contributes to the adverse neonatal outcomes [25, 26, 27]. The risk of medically indicated early preterm birth increases due to preeclampsia and gestational diabetes [26]. This risk is further increased in patients with gestational weight gain that is above the Institute of Medicine's recommendations [28, 29].

Fetal macrosomia, maternal obesity and excessive weight gain during pregnancy are associated with later obesity in childhood and adolescence [30,31]. Obese women have a higher risk of caesarean section than women of normal weight $[21,32]$, and this explains the decrease in vaginal delivery in obese women [33, 34, 35].

To our knowledge, this study is one of the first works in Lebanon. It surely has an important impact on the local national scale but also on the international one. Fewer studies are reported from Middle Eastern countries due to low data collection in these countries. Studies, such as this one from Lebanon, will help draw general guidelines to reduce pregnancy risks related to obesity that are applicable to similar countries. This work explores a sample of 1308 pregnant women from Northern Lebanon in order to delineate the influential factors on mother and baby health complications, especially early pregnancy, high Body Mass Index (BMI)I, weight gain and multiparty, in addition to social status and lifestyle indicators.

\section{MATERIALS AND METHODS}

This is a retrospective cohort study for 1308 women that gave birth between January 2014 and January 2016. Once women consented, anthropometric data including height, weight at the beginning of pregnancy, gestational age estimated by the last menstrual period or ultrasound examination and health status, were collected from the medical records in two private gynecology clinics and one primary health care center. Maternal and fetal health data were obtained from the medical records in five hospitals in NorthLebanon (private and public Islamic hospitals, Sayyidet Zgharta hospital, governmental hospital of Akkar and governmental hospital of Tripoli). A questionnaire including Socio-demographic (income, place of residence, parity) and lifestyle data (smoking habits, physical activity) were gathered by a telephone call to each woman, all of them were responsive with no missing data. A Body Mass Index (BMI) of each woman was calculated by using the formula: Weight $(\mathrm{kg}) /$ Height $\left(\mathrm{m}^{2}\right)$.

Women were divided into 3 weight groups based on WHO guidelines [36] with Normal: BMI of 18.5-24.9, Overweight: BMI of 25-29.9 and Obese: BMI of 30 and above. Underweight group was discarded due to a negligible number of representatives. Were also discarded, samples with incomplete data, women aged under 17 or above 35 due to their high risk of developing complications, women with chronic diseases (hypertension or diabetes) or suspected to have fetuses with congenital malformation.

The final data matrix included 1308 rows and 20 columns. Descriptive statistics, Chi-square tests, Principal Component for categorical variables, binary logistic regression, and correlation were used to analyze the data and evaluate the association between the complications and the other type of variables. A probability value of $5 \%$ was used to determine statistical significance. SPSS version 23.0 was used to carry out these analyses.

\section{RESULTS}

Among the 1308 women constituting the study sample, 658 women had normal BMI $(50.3 \%), 344$ in were overweight $(26.3 \%)$, and 306 were obese $(23.4 \%)$. The majority of our sample was urban $(80 \%)$, working women with high education and in a good income household (Table I). They were aged between 18-34 years. They have dominantly university level education (77\%) along with their husbands $(87 \%)$. About three quarters of the interviewed women $(74 \%)$, reported having a job. Almost all the husbands reported having a job (96\%) with a good social level (income) (79\%).

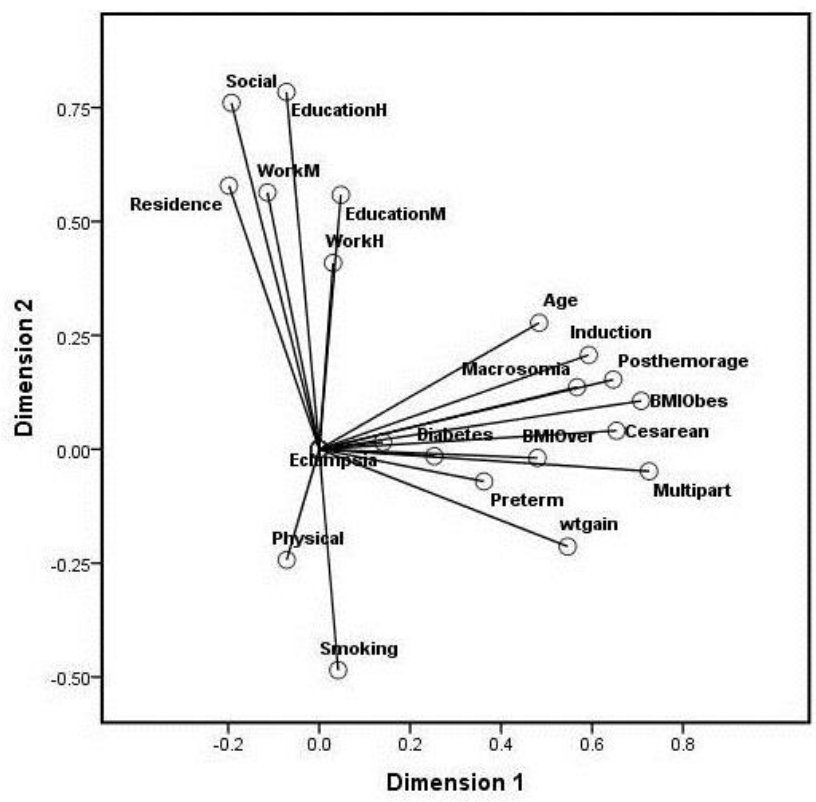

Fig. 1 Projection of the first (dimension1) and second (dimension2) axes of Principal component analysis for categorical data including all the demographic, lifestyle and health indicators.

At the time of the recruitment, $46 \%$ of the women had no child, $24 \%$ had one, $11 \%$ had 2 children, $15 \%$ had 3 children and $4 \%$ had 4 or more. The percentage of mothers who smoked during pregnancy was $6.7 \%$. The majority $(93 \%)$ of women did not exercise at all with $67.5 \%$ having normal weight gain during pregnancy according to their BMI.

The most frequent health complications related to pregnancy were emergency cesarean-section (c-section surgery 
to deliver a baby due to medical risk) with 407 cases, followed by post-partum hemorrhage (blood loss higher than 500 $\mathrm{mL} /$ day) with 328 , induced labor (stimulation of uterine contractions during pregnancy) with 307 and macrosomia (newborn weight $>4000$ grams) with 149 cases (Table I). The least frequent complications were preterm (delivery before $37^{\text {th }}$ week of gestation), gestational diabetes (woman without diabetes develops high blood sugar levels during pregnancy), low birth weight (weight $<2500$ grams), eclampsia (high blood pressure results in seizures during pregnancy) and finally stillbirth (baby death) with only two cases.

In order to explore the relation between the pregnancy and fetal complications along with the rest of the confounding factors, the 1308 profiles were analyzed using Principal Component Analysis (PCA) for categorical data (Fig. 1). The analysis revealed a high variability in the data with the first two axes extracting only $33 \%$ of the total variance. Nevertheless, the two axes (Fig. 1) were clearly defined by different indicators with the first axis reflecting the obesitycomplication relation, while the second axis was defined by social and lifestyle indicators of such as income, educational level, parental jobs, residence, physical activity and smoking habits. The main contributions to the first axis were the mother's BMI, weight gain, parity and age along with the pregnancy complications, especially the most prevalent ones. Hence, the mother and baby complications seem to be mainly correlated with weight indicators in particular the mother's BMI.

Indeed, the Chi-square tests results (Table II) also shows that for almost all adverse health effects for the mother and the baby, the proportion of obese women was significantly greater with a p-value less than 0.05 except for stillbirth (Table II). For C-section, that is a common adverse outcome for obese women, the proportion increased from $17.9 \%$ for normal weight mothers to $56.9 \%$ for obese women. Similarly, for induction of labor, the proportion rose from $13.5 \%$ for normal weight mothers to $46.1 \%$ for obese mothers,

Table I: Demographic, social and health characteristics (N: number among 1308 women and percentage).

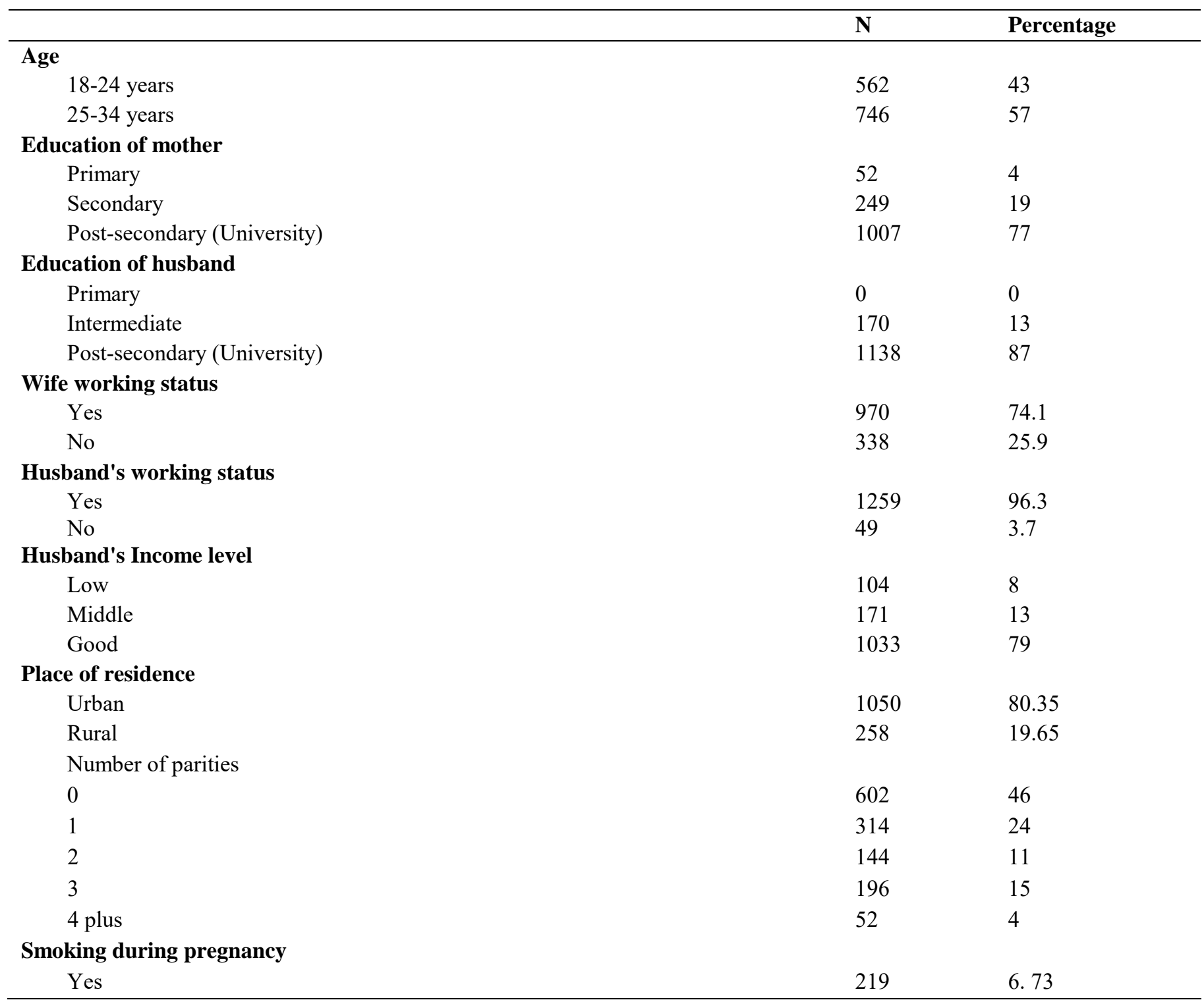




\begin{tabular}{|c|c|c|}
\hline No & 1089 & 93.27 \\
\hline \multicolumn{3}{|l|}{ Do you exercise? } \\
\hline No & 1107 & 93.27 \\
\hline Yes & 201 & 6.73 \\
\hline \multicolumn{3}{|l|}{ BMI categorical } \\
\hline Normal & 658 & 50.3 \\
\hline Overweight & 344 & 26.3 \\
\hline Obese & 306 & 23.4 \\
\hline \multicolumn{3}{|l|}{ Weight gain } \\
\hline Normal & 883 & 67.5 \\
\hline Excess & 425 & 32.5 \\
\hline \multicolumn{3}{|l|}{ Maternal Complications } \\
\hline Gestational diabetes & 52 & 4.0 \\
\hline Eclampsia & 24 & 1.8 \\
\hline C-section & 407 & 31.1 \\
\hline Induction of labor & 307 & 23.5 \\
\hline Post hemorrhage & 328 & 25.1 \\
\hline \multicolumn{3}{|l|}{ Baby complications } \\
\hline Macrosomia & 149 & 11.4 \\
\hline Preterm & 67 & 5.1 \\
\hline low birth weight & 54 & 4.1 \\
\hline \multicolumn{3}{|l|}{ APGAR score } \\
\hline 5 & 12 & 0.9 \\
\hline 6 & 21 & 1.6 \\
\hline 7 & 62 & 4.7 \\
\hline 8 & 155 & 11.9 \\
\hline 9 & 1058 & 80.9 \\
\hline \multicolumn{3}{|l|}{ Baby complications } \\
\hline Macrosomia & 149 & 11.4 \\
\hline
\end{tabular}

along with post-partum hemorrhage proportions that increased from $4.9 \%$ for normal weight to $58.8 \%$ for obese mothers. This complication is defined as the loss of more than $500 \mathrm{~mL}$ or $1,000 \mathrm{~mL}$ of blood within the first 24 hours following childbirth. This increase in proportions for obese women was also observed for the other less frequent complications such as eclampsia and gestational diabetes even if the differences were smaller. For adverse fetal outcomes, comparable findings were also observed with macrosomia proportion increasing from $1.5 \%$ for normal weight mothers to $31 \%$ for obese mothers.

The odds ratios were calculated for normal BMI women with those versus obese BMI women and then versus overweight BMI women.

The risk of developing complications during pregnancy, based on adjusted logistic regression odds ratios, was statistically significant $(\mathrm{p}<0.05)$ and much higher in obese group except for gestational diabetes and eclampsia (Table III). The adjusted odds ratios for the complications were 2.1
(1.3 - 3.2) for C-section, $2.4(1.5$ - 3.7) for labor induction, $7.4(2.9$ - 18.5) for preterm, $9.8(5.7-16.8)$ for post hemorrhage and 15.3 (6.9 - 34) for macrosomia. The lowest values of odds ratios were observed for the less frequent complications (pre-eclampsia, gestational diabetes).

In addition to the obese mother's BMI, parity and weight gain during pregnancy showed statistically significant odds ratios in the logistic regression models of many pregnancy complications (Table IV). complications the values in bold In Table $\mathrm{V}$ are significant at the level 5\%.

Moderate to low correlations (correlation coefficients $\leq 0.606$ ) were found between the complications and the rest of the variables. The highest correlation coefficients were obtained for the BMI for obese women and multiparity (Table $\mathrm{V})$. As the number of children increases, the percentage of complications increases. The age gave also a similar effect even though the correlation values were not as high as for the multiparty variable. 
Table II: Prevalence and statistical significance (p: Probability for Chi-square test) of maternal and fetal complications for the different BMI groups.

\begin{tabular}{|c|c|c|c|c|}
\hline \multicolumn{5}{|c|}{ BMI } \\
\hline Maternal complications & Normal & Overweight & Obese & $P$-value \\
\hline Pre-eclampsia & $1.40 \%$ & $2.90 \%$ & $5.90 \%$ & $<0.0001$ \\
\hline Eclampsia & $1.10 \%$ & $1.70 \%$ & $3.60 \%$ & $<0.02$ \\
\hline C-section & $17.90 \%$ & $33.70 \%$ & $56.90 \%$ & $<0.001$ \\
\hline Gestational diabetes & $2.10 \%$ & $3.80 \%$ & $8.20 \%$ & $<0.0001$ \\
\hline Induced labor & $13.50 \%$ & $22.40 \%$ & $46.10 \%$ & $<0.0001$ \\
\hline Post-partum hemorrhage & $4.90 \%$ & $33.70 \%$ & $58.80 \%$ & $<0.0001$ \\
\hline Sever post hemorrhage & $0.30 \%$ & $1.70 \%$ & $3.60 \%$ & 0.037 \\
\hline \multicolumn{5}{|l|}{ Fetal complications } \\
\hline Low Apgar score & $0.3 \%$ & $2.6 \%$ & $7.2 \%$ & $<0.0001$ \\
\hline Preterm & $1.1 \%$ & $6.4 \%$ & $12.4 \%$ & $<0.0001$ \\
\hline Very preterm & $0.2 \%$ & $1.5 \%$ & $2.6 \%$ & 0.002 \\
\hline Macrosomia & $1.5 \%$ & $12.8 \%$ & $31 \%$ & $<0.0001$ \\
\hline Low birthweight & $5.8 \%$ & $3.8 \%$ & $1 \%$ & 0.002 \\
\hline Stillbirth & $0.2 \%$ & $0 \%$ & $0.3 \%$ & 0.568 \\
\hline
\end{tabular}

Among the different complications, weight gain showed the highest correlation with emergency c-section, which may explain at least part of these interventions. It is also noteworthy that weight gain was the only indicator that showed relatively significant correlation with gestational diabetes. In fact, all women that presented gestational diabetes had excessive weight gain. Finally, it seems that incidence of cesarean was inversely correlated with living in the village (Table V).

\section{DISCUSSION}

This retrospective study showed that mother and baby weight parameters seem to be good indicators of pregnancy complications such as emergency c-section, post-partum hemorrhage, induction of labor, preterm delivery and macrosomia. An important body of published work have shown similar results in particular the correlation of obstetric complications to obesity [37] including in the MENA region $[12,14]$.

High rates of c-section delivery constitute an important health problem that was mainly associated to maternal obesity [38]. In our sample, the incidence of emergency c-section increased from about $17.9 \%$ for normal weight group to $56.9 \%$ in the obese group comparable to the incidence in Thai obese women of 52\% [39]. Obese women present a higher risk to undergo c-section [40]. The elevated incidence of intra-partum c-section, among pregnant obese women, has been related predominately to failure to progress [41] due to the inefficient uterine activity in labor. Particularly, obesity affects the intra-partum myometrium contractility, the tract diameter (route of delivery) and the size of the baby due to macrosomia [41].

Table III: Adjusted odds ratios values compared for the groups of obese and overweight women based on their BMI.

\begin{tabular}{ccccc}
\hline Characteristic & $\begin{array}{c}\text { Adjusted odds ratio obese vs } \\
\text { normal } \begin{array}{c}\text { (95\% confidence } \\
\text { interval) }\end{array}\end{array}$ & $\mathrm{p}$ value & $\begin{array}{c}\text { Adjusted odds ratio overweight vs } \\
\text { normal }(95 \% \text { confidence interval) }\end{array}$ & $\mathrm{p}$ value \\
\hline Gestational diabetes & - & $\mathrm{NS}$ & - & $\mathrm{NS}$ \\
Eclampsia & - & $\mathrm{NS}$ & - & $\mathrm{NS}$ \\
Cesarean delivery & $2.1(1.3-3.2)$ & 0.001 & $1.8(1.2-2.7)$ & 0.005 \\
Labor induction & $2.4(1.5-3.7)$ & 0.000 & - & $\mathrm{NS}$ \\
$\quad \begin{array}{c}\text { Post-partum } \\
\text { hemorrhage }\end{array}$ & $9.8(5.7-16.8)$ & 0.000 & $10.1(5.7-17.7)$ & 0.000 \\
Macrosomia & $15.3(6.9-34)$ & 0.000 & $4.1(1.7-9.5)$ & 0.001 \\
Preterm & $7.4(2.9-18.5)$ & 0.000 & $4.1(1.7-9.5)$ & 0.001 \\
\hline
\end{tabular}

NS: not statistically significant. 
Failure to progress may also explain the high prevalence of labor induction observed in our sample (odds ratio 2.4 in obese women). Previous studies have also reported that women with high BMI were more likely to have their labor induced [42]. Many studies have reported that the size of the fetus can also be a determinant factor for delivery mode. Our findings corroborate this since $70 \%$ of women who underwent c-section had macrosomic babies that can cause dystocia due to the large size of the fetus [43].

Furthermore, our sample showed a high incidence of macrosomia that is probably related to the prevalence of obese mothers that accounted for $64 \%$ of the macrosomic babies.

The risk of macrosomia depends on the pre-pregnancy weight [44]. Nevertheless, macrosomia can also be associated to gestational weight gain (GWG). In fact, being overweight and obese before pregnancy, and excessive weight gain during pregnancy may lead to increased concentrations of glucose, amino acids and free fatty acids in pregnant women [45], thereby increasing the risk of macrosomia.

Our results showed a statistically significant correlation between GWG and macrosomia in accordance to those to those of Deruelle [46] and Yang et al. [47]. For Lebanese women in our study, weight gain was significantly associated to many maternal complications and macrosomia probably due to inadequate diet affecting the baby and the mother's weight. Indeed El-Rafei et al. [19] suggested that
Lebanese culture still equates newborn's health and growth to its high birth weight.

Obesity has also been associated to post-partum hemorrhage [41]. Another study [40] found that post-partum hemorrhage is considered as one of several adverse maternal outcomes associated with obesity. Our data support this with a high prevalence of post-partum hemorrhage in the obese women sample even after adjustment of odds ratios by potential confounding factors. It is certainly, at least partially, associated to the high incidence of c-section leading to complications of surgery in obese patients as was reported in other investigations [41]. A cohort study [48] including $1,114,071$ women showed a rapid but small increase of uterine hemorrhage risk with increasing BMI. The high incidence observed in our sample maybe related to defining post-partum hemorrhage as a loss of blood higher than $500 \mathrm{ml}$ per day instead of $1000 \mathrm{ml}$ per day.

Mother age and multiparity seem to be additional important confounding factors that correlated well with the weight indicators as well as the pregnancy complications. Maternal complications proportions increased from $29.8 \%$ for women aged lower than 24 to $66.5 \%$ for those aged above 25 . In addition, obese women tend to be older and more likely multiparous [39]. In our sample, $98.5 \%$ of the mothers who underwent c-section were also multiparous. Women parity can also increase the incidence of c-section [49]. Similarly, to csection, macrosomia seems correlated with multiparity as other studies have also reported [50].

Table IV: Probability values for odds ratios between complications and confounding parameters of weight and social indicators.

\begin{tabular}{|c|c|c|c|c|c|c|c|}
\hline & BMI Obese & $\begin{array}{c}\text { Weight } \\
\text { gain }\end{array}$ & Parity & Age & Smoking & $\begin{array}{c}\text { Physical } \\
\text { activity }\end{array}$ & Residence \\
\hline Cesarean section & 0.000 & 0.000 & 0.000 & 0.000 & 0.250 & 0.026 & 0.000 \\
\hline Labour Induction & 0.000 & 0.011 & 0.003 & 0.001 & 0.000 & 0.267 & 0.001 \\
\hline $\begin{array}{l}\text { Post-partum } \\
\text { hemorrhage }\end{array}$ & 0.000 & 0.004 & 0.000 & 0.734 & 0.003 & 0.000 & 0.159 \\
\hline Macrosomia & 0.000 & 0.004 & 0.000 & 0.742 & 0.206 & 0.004 & 0.000 \\
\hline Diabetes & 0.114 & 0.988 & 0.104 & 0.000 & 0.194 & 0.997 & 0.001 \\
\hline Eclampsia & 0.401 & 0.074 & 0.010 & 0.522 & 0.037 & 0.742 & 0.822 \\
\hline Preterm & 0.000 & 0.006 & 0.053 & 0.687 & 0.620 & 0.014 & 0.028 \\
\hline
\end{tabular}

Smoking and physical activity have also been shown to affect complications during pregnancy [51]. Pregnant smokers in our study were more likely to have complications with $67 \%$. In Jordan, smoking during pregnancy was found to increase the risk of induced labor by $71 \%$ [52]. In contrast, regular physical activity during pregnancy provides many health and social benefits and lowers the risk of many pregnancy complications [51]. Indeed, the proportion of mothers who experienced pregnancy complications was lower among mothers who exercised with only $36 \%$.

Place of residence was significantly associated with adverse outcomes with $67.7 \%$ mothers residing in a rural setting experiencing complications versus $46.4 \%$ for city dwellers. Indeed, pre-eclampsia [53] and pre-mature delivery
[54] have been reported to be more common for rural women in other countries.

Although pre-eclampsia and preterm were less frequent complications, they presented higher proportions for the obese group in agreement with data reported by ScottPillai et al. [55]. Sujathaa et al. [2] have reported significantly higher frequencies in obese group in comparison to normal group. The effect of obesity on preterm delivery remains

controversial with some authors relating it to maternal underweight [56]. In fact, a systematic review and metaanalyses [57] showed that singletons born to underweight women have higher risks of preterm birth and LBW than those born to women with normal weight. Other authors relate it to high BMI [58]. Kosa et al. [59] attributed the controversial 
results to differences in race and ethnicity along with inconsistent definitions of obesity and preterm delivery. Increased risk of preterm delivery was also reported for overweight/obese pregnant women [55].

Similarly, to pre-eclampsia and preterm, gestational diabetes prevalence was also rather low as reported by Sabbagh et al. [60] in another study from Lebanon. Even if diabetes did not seem to be correlated to the BMI or other weight indicators, all women with gestational diabetes presented an excess weight gain.

Table V: Pearson correlation coefficients between obstetric complications and mothers' characteristics (numbers in bold were statically significant at the level $5 \%$ ).

\begin{tabular}{lccccc}
\hline & Multiparity & Age & $\begin{array}{c}\text { BMI } \\
\text { Obese }\end{array}$ & $\begin{array}{c}\text { Weight } \\
\text { gain }\end{array}$ & Residence \\
\hline $\begin{array}{l}\text { Cesarean } \\
\text { section }\end{array}$ & $\mathbf{0 . 3 6 6}$ & $\mathbf{0 . 2 9 5}$ & $\mathbf{0 . 3 9 4}$ & $\mathbf{0 . 3 7 7}$ & -0.191 \\
$\begin{array}{l}\text { Post-partum } \\
\text { hemorrhage }\end{array}$ & $\mathbf{0 . 4 3 2}$ & 0.225 & $\mathbf{0 . 6 0 6}$ & 0.083 & -0.020 \\
$\begin{array}{l}\text { Labor } \\
\text { Induction }\end{array}$ & $\mathbf{0 . 3 0 1}$ & $\mathbf{0 . 3 2 8}$ & $\mathbf{0 . 3 5 6}$ & 0.249 & -0.071 \\
Macrosomia & $\mathbf{0 . 3 2 1}$ & 0.197 & $\mathbf{0 . 4 4 1}$ & 0.184 & 0.062 \\
Preterm & 0.145 & 0.098 & 0.251 & 0.203 & -0.007 \\
Diabetes & 0.117 & 0.052 & 0.143 & 0.287 & 0.022 \\
Eclampsia & 0.103 & 0.051 & 0.087 & 0.012 & -0.004 \\
\hline
\end{tabular}

These low incidences of gestational diabetes, preterm and pre-eclampsia in our study could be related to the nature of the sampled women that were in majority highly educated with a good social status and hence would have benefited from a better medical assistance and awareness of the dangers of these complications.

\section{CONCLUSION}

Obesity has becoming an epidemic. Women tend to have complications during pregnancy due to their high prepregnancy BMI, which contributes to several outcomes, such as c-section, postpartum hemorrhage, induction of labor, preterm and macrosomia in newborns. Other factors affect maternal outcomes such as sedentary lifestyle, smoking, excessive weight gain and lack of health care.

This study showed that most pregnancy complications in a Northern Lebanon population seem to be related to weight indicators especially early pregnancy obese BMI, weight gain and macrosomia. Hence, there should be an increased awareness of the dangers of these factors in this population, through programs of more adequate dieting, consulting and frequent follow up during the whole pregnancy.

This study is local and conducted in Lebanon. However, obesity and overweight among women is widespread all over the world. The results of other studies in various countries from Africa, Asia and Europe are similar as mentioned in the text, which show that the problem is not only of interest in developing countries such as Lebanon, but is also a global issue. We focused in this study on the effect of weight gain during pregnancy and its link to health problems. This would help doctors in the world to guide pregnant women to follow a diet to prevent excessive weight gain, which leads to reducing the risk of some health problems such as gestational diabetes and c-section during pregnancy and possibly a normal delivery.

\section{ACKNOWLEDGMENTS}

We thank all the hospitals, health clinics and primary care centers for giving us the permission to collect the data from their medical records and thank all the women who accepted and consented to be part of our study.

\section{References}

[1] World Health Organization. "The World Health Report: make every mother and child count". ISBN 924156290 0, (2005). Retrieved at: https://www.who.int/whr/2005/en/.

[2] V. Sujathaa, K. Sharmaa, K. Rajesha, "High body mass index in pregnancy, its effects on maternal and fetal outcome", J. Clin. Gynecol. Obstet., vol. 1, no. 1, pp. 15-18, 2012.

[3] World Health Organization (WHO). "Make every mother and child count. In: Annual number of deaths by cause for neonates in WHO regions, estimates for 2000-2003", Available at: http://www.who.int/whr/2005/annex/en (2005).

[4] $\mathrm{Ng}$, M. et al. "Global, regional, and national prevalence of overweight and obesity in children and adults during 19802013: a systematic analysis for the Global Burden of Disease Stud 2013". Lancet 384, 766-81 (2014).

[5] R. F.Goldstein, S. K. Abell, , S.Ranasinha, , M. L. Misso, J.A. Boyle, C. L. Harrison, ,\& H.Hegaard,. Gestational weight gain across continents and ethnicity: systematic review and metaanalysis of maternal and infant outcomes in more than one million women. BMC medicine, 16(1) (2018), 153.

[6] Euro-Peristat Project. European Perinatal Health Report. Core Indicators of the Health and Care of Pregnant Women and Babies in Europe in 2015. 2018. Available online: https://www.europeristat.com/images/EPHR2015_web_hy perlinked_Euro-Peristat.pdf (accessed on 20 November 2018).

[7] M.Simko, A. Totka, D. Vondrova, , M.Samohyl, J.Jurkovicova, M.Trnka, \& Argalasova, L. Maternal body mass index and gestational weight gain and their association with pregnancy complications and perinatal conditions. International journal of environmental research and public health, 16(10) (2019), 1751.

[8] J.Marchi, J., M.Berg, M., A.Dencker , E. K.Olander, \& C.Begley, (2015). Risks associated with obesity in pregnancy, for the mother and baby: a systematic review of reviews. Obesity Reviews, 16(8), 621-638.

[9] Onubi, O. J., Marais, D., Aucott, L., Okonofua, F., \& Poobalan, A. S. (2016). Maternal obesity in Africa: a systematic review and meta-analysis. Journal of Public Health, 38(3), e218-e231.

[10] C. Chen, X.Xu. \& Y Yan. (2018). Estimated global overweight and obesity burden in pregnant women based on panel data model. PLoS One, 13(8), e0202183. 
[11] H. Zaiton, E. Elsabagh, "Risk factors of obesity on maternal and perinatal outcomes among pregnant women", J. American Sci. 7 (2011) 74-83.

[12] L. Mochhoury, R. Razine, J. Kasouati, M. Kabiri, A. Barkat, "Body mass index, gestational weight gain, and obstetric complications in Moroccan population", J. Pregnancy 2013 (2013) ID 379461.

[13] C. Aydin, A. Baloglu, A. Yavuzcan, A. Inci, "The effect of body mass index value during labor on pregnancy outcomes in Turkish population (obesity and pregnancy outcomes)", Arch. Gynecol. Obstet. 281(1) (2010) 49-54.

[14] Z. Yekta, H. Ayatollahi, R. Porali, A. Farzin, "The effect of prepregnancy body mass index and gestational weight gain on pregnancy outcomes in urban care settings in Urmia-Iran" BMC Pregnancy Childb. 6(1) (2006) 15.

[15] P. Mirmiran, S. Farahani, R. Kazemzadeh, F. Azizi, "Childhood obesity in the Middle East: A review", E. Mediterr. Health J. 16(9) (2010) 1009-17.

[16] R. El Hage, F. Bachour, W. Khairallah, F. Bedran, N. Maalouf, E. Zakhem, G. Maalouf, "The influence of obesity and overweight on hip bone mineral density in Lebanese women", J. Clin. Densitom. 17(1) (2014) 216-217.

[17] S. Mallat, A. G. Geagea, R. A. Jurjus, A. Rizkallah, D. Oueidat, M. Matar, A. R. Jurjus, "Obesity in Lebanon: A national problem", World J. Cardiovasc. Dis. 6(6) (2016) 166.

[18] S. Zgheib, M. Kacim, K. Kostev, "Prevalence of and risk factors associated with cesarean section in Lebanon - A retrospective study based on a sample of 29,270 women, Women Birth" 30(6) (2017) 265-271.

[19] R. El-Rafei, H. A. Abbas, L. Charafeddine, P. Nakad, A. D. Al BizriHamod, K. A. Yunis, "Association of Pre-Pregnancy Body Mass Index and Gestational Weight Gain with Preterm Births and Fetal Size: An Observational Study from Lebanon", Paediatr. Perinat. Epidemiol. 30(1) (2016) 38-45.

[20] K. M. Rasmussen, A. L. Yaktine, "Weight gain during pregnancy: reexamining the guidelines". Institute of Medicine. National Academies Press (2009).

[21] S. Kim, Y. Zhu, K. Grantz, et al. "Obstetric and neonatal risks among obese women without chronic disease". Obstet Gynecol. 2016;128:104-112.

[22] S. Lisonkova, G. Muraca, J.Potts, et al. "Association between prepregnancy body mass index and severe maternal morbidity". JAMA. 2017;318:1777-1786.

[23] L. Schummers, J. Hutcheon, L. Bodnar, E. Lieberman, K. Himes, "Risk of adverse pregnancy outcomes by prepregnancy body mass index: a population-based study to inform prepregnancy weight loss counseling". Obstet Gynecol. 2015;125:133-143.

[24] U.Moll, H. Olsson, M. Landin-Olsson. "Impact of pregestational weight and weight gain during pregnancy on long-term risk for diseases". PLoS One. 2017;12 e0168543.

[25] S. Kim, P. Mendola, Y. Zhu, B. Hwang, K. Grantz, "Spontaneous and indicated preterm delivery risk is increased among overweight and obese women without prepregnancy chronic disease". BJOG. 2017; 124:1708-1716.

[26] S. Cnattingius, E. Villamor, S. Johansson et al. "Maternal obesity and risk of preterm delivery". JAMA. 2013; 309:23622370 .

[27] G. Shaw, P. Wise, J. Mayo et al. "Maternal prepregnancy body mass index and risk of spontaneous preterm birth". Paediatr Perinat Epidemiol. 2014;28:302-311.

[28] M. Faucher, M. Hastings-Tolsma, J. Song, D.Willoughby, S. Bader, "Gestational weight gain and preterm birth in obese women: a systematic review and meta-analysis". BJOG. 2016; 123:199-206.
[29] American College of Obstetricians and Gynecologists. ACOG Committee opinion no. 548: "weight gain during pregnancy". Obstet Gynecol. 2013; 121:210-212.

[30] H. Castillo, I. Santos, A. Matijasevich, "Relationship between maternal pre-pregnancy body mass index, gestational weight gain and childhood fatness at 6-7 years by air displacement plethysmography". Matern Child Nutr. 2015; 11:606-617.

[31] J. Woo Baidal, L. Locks, E. Cheng, T.Blake-Lamb, M. Perkins, E. Taveras, "Risk factors for childhood obesity in the first 1,000 days: a systematic review". Am J Prev Med. 2016; 50:761-779.

[32] P. Ovesen, S. Rasmussen, U. Kesmodel, "Effect of prepregnancy maternal overweight and obesity on pregnancy outcome". Obstet Gynecol. 2011; 118:305-312.

[33] R. Scott-Pillai, D. Spence, C. Cardwell, A. Hunter, V. Holmes. "The impact of body mass index on maternal and neonatal outcomes: a retrospective study in a UK obstetric population, 2004-2011”. BJOG. 2013; 120:932-939.

[34] C. Athukorala, A. Rumbold, K. Willson, C. Crowther, "The risk of adverse pregnancy outcomes in women who are overweight or obese". BMC Pregnancy Childbirth. 2010;10.

[35] S. Chu, S. Kim, C. Schmid et al. "Maternal obesity and risk of cesarean delivery: a meta-analysis". Obes Rev. 2007; 8:385394.

[36] World Health Organization (WHO), "Global Strategy on Diet, Physical Activity and Health" [cited 2020 Aug 31], https://www.who.int/dietphysicalactivity/childhood what/en/.

[37] L. Liu, Y. Ma, N. Wang, W. Lin, Y. Liu, D. Wen, "Maternal body mass index and risk of neonatal adverse outcomes in China: a systematic review and meta-analysis", BMC Pregnancy Childb., 19(1) (2019) 105.

[38] W. Al-Kubaisy, M. Al-Rubaey, R.A. Al-Naggar, B. Karim, N.A. Mohd Noor, "Maternal obesity and its relation with the cesarean section: A hospital based cross sectional study in Iraq", BMC Pregnancy Childb. 14 (2014) 235.

[39] K. Saereeporncharenkul, "Correlation of BMI to pregnancy outcomes in Thai women delivered in Rajavithi Hospital", J. Med. Assoc. Thai. 94 (2011) 52-58.

[40] S. Bhattacharya, D. Campbell, W. Liston, "Effect of body mass index on pregnancy outcomes in Nulliparous women delivering singleton babies", BMC Public Health 7(1) (2007)168.

[41] E. M. Fyfe, J. M. Thompson, N. H. Anderson, K. M. Groom, L. M. McCowan, "Maternal obesity and postpartum hemorrhage after vaginal and caesarean delivery among nulliparous women at term: a retrospective cohort study", BMC Pregnancy Childb. 12(1) (2012) 112.

[42] S. Arrowsmith, S. Wray, S. Quenby, "Maternal obesity and labour complications following induction of labour in prolonged pregnancy", BJOG-Int. J. Obstet Gy. 118(5) (2011) 578-588.

[43] J. L. Weiss, F. D. Malone, D. Emig, R. H. Ball, D. A. Nyberg, C. H. Comstock, S. R. Carr, "Obesity, obstetric complications and cesarean delivery rate-a population-based screening study", Am. J. Obstet. Gynecol. 190(4) (2004) 1091-1097.

[44] N. J. Sebire, M. Jolly, J. P. Harris, J. Wadsworth, M. Joffe, R. W. Beard, S. Robinson, "Maternal obesity and pregnancy outcome: a study of 287213 pregnancies in London", Int. J. Obes. 25(8) (2001) 1175.

[45] Hull HR, Thornton JC, Ji Y, Paley C, Rosenn B, Mathews P, et al. "Higher infant body fat with excessive gestational weight gain in overweight women", Am J Obstet Gynecol. 2011;205(3): 211.e1-7

[46] P. Deruelle, "Obésité et grossesse », Gynecol. Obstet. Fertil. 39(2) (2011) 100-105.

[47 S. Yang, A. Zhou, C. Xiong, R. Yang, B.A. Bassig, R. Hu, Y. Zhang, C. Yao, Y. Zhang, L. Qiu, Z. Qian, E. Trevathan, L. Flick, S. Xu, Y. Wang, W. Xia, T. Zheng, B. Zhang, "Parental Body Mass Index, Gestational Weight Gain, and Risk of 
Macrosomia: a Population-Based Case-Control Study in China", Paediatr. Perinat. Epidemiol. 29 (2015) 462.

[48] M. Blomberg, "Maternal obesity and risk of postpartum hemorrhage", Obstet. Gynecol. J. 118(3) (2011) 561-8.

[49] A.U. Derbent, A. Karabulut, M. Yıldırım, S. A. Simavlı, N.Ö Turhan, "Evaluation of risk factors in cesarean delivery among multiparous women with a history of vaginal delivery", J. Turk. Ger. Gynecol. Assoc. 13(1) (2012) 15.

[50] L. Sekhavat, R. Fallah, "Could maternal pre-pregnancy body mass index affect Apgar score?", Arch. Gynecol. Obstet. 287(1) (2013) 15-8.

[51] B. Price, S. B. Amini, K. Kappeler, "Exercise in pregnancy: effect on fitness and obstetric outcomes a randomized trial", Med. Sci. Sport Exer. 44 (12) (2012) 2263-2269.

[52] H. Amasha, M. Jaradeh, "Effect of active and passive smoking during pregnancy on its outcomes", BMC Pregnancy Childb. 17 (2012) 235.

[53] P. Chowa, C. Lin, F. Goma, J. Paul, "Prevalence of hypertension among women of child bearing age in Zambia", Med. J. Zambia. 38(3) (2011) 3-8.

[54] M. Abdel-Latif, B. Bajuk, J. Oei, T. Vincent, L. Sutton, K. Lui, "Does rural or urban residence make a difference to neonatal outcome in premature birth? A regional study in Australia", Arch. Dis. Child. Fetal Neonat. 91(4) (2006) F251-F256.

[55] R. Scott-Pillai, D. Spence, C.R. Cardwell, A. Hunter, V.A. Holmes, "The impact of body mass index on maternal and neonatal outcomes: a retrospective study in a UK obstetric population 2004-2011", BJOG. 120(8) (2013) 932-9.

[56] A.S. Khashan, L.C. Kenny, "The effects of maternal body mass index on pregnancy outcome", Eur. J. Epidemiol. 24(11) (2009) 697.

[57] Zhen Han, Sohail Mulla, Joseph Beyene, Grace Liao, Sarah D McDonald. "Maternal underweight and the risk of preterm birth and low birth weight: a systematic review and meta-analyses". Int J Epidemiol (2011) doi: 10.1093/ije/dyq195.

[58] J. Madan, M. Chen, E. Goodman, J. Davis, W. Allan, O. Dammann, Maternal obesity, "gestational hypertension, and preterm delivery", J. Matern. Fetal Neonatal. Med. 23 (2010) $82-88$.

[59] J.L. Kosa, S. Guendelman, M. Pearl, S. Graham, B. Abrams, M. Kharrazi,"The association between pre-pregnancy BMI and preterm delivery in a diverse southern California population of working women", Matern. Child Health J. 15(6) (2011) 772781.

[60] M. Sabbagh, Z. Mehanna, L. Abi Farraj, A. Salloum, P. Zallouab, "Gestational diabetes mellitus and macrosomia predispose to diabetes in the Lebanese population", J. Clin. Transl. Endocrinol. 16 (2019) 1-5.

\section{Contribution of individual authors to the creation of a scientific article (ghostwriting policy)}

Mayssa Traboulsi collected the data and wrote the first draft of the paper.

Abdellatif Boussaid carried out the statistical analysis, writing the paper and supervising.

Zainab E. El Alaoui-Talibi provided guidance for conducting the study and writing the paper.
Data from this study will be available on request to the corresponding author:

Mayssa A.Traboulsi, E-mail:Mayssatr@gmail.com

\section{Sources of funding for research presented in a scientific article or scientific article itself}

No special funds were used in this study.

\section{Creative Commons Attribution License 4.0 (Attribution 4.0 International, CC BY 4.0)}

This article is published under the terms of the Creative Commons Attribution License 4.0 https://creativecommons.org/licenses/by/4.0/deed.en US 